\title{
Strength grading of Norway spruce structural timber: revisiting property relationships used in EN 338 classification system
}

Journal Article

Author(s):

Steiger, Rene; Arnold, Martin

Publication date:

2009

Permanent link:

https://doi.org/10.3929/ethz-b-000106759

Rights / license:

In Copyright - Non-Commercial Use Permitted

Originally published in:

Wood Science and Technology 43(3-4), https://doi.org/10.1007/s00226-008-0221-6 


\title{
Strength grading of Norway spruce structural timber: revisiting property relationships used in EN 338 classification system
}

\author{
René Steiger · Martin Arnold
}

Received: 21 December 2007/Published online: 30 September 2008

(C) Springer-Verlag 2008

\begin{abstract}
Solid timber for structural applications has to be strength graded prior to its use. In order to remain economic the grading process usually focuses on the most important physical and mechanical properties: density, modulus of elasticity (MOE) and bending strength. Based on respective limits given in standards, the timber is assigned to strength classes. Additional mechanical properties such as tensile and compression strength parallel to the grain are derived from the basic property values by empirical relationships. The objective of this study was to review some of these property relationships based on recently compiled large data sets as a contribution for a future revision of the grading standards. Based on mechanical tests of Norway spruce structural timber with different cross-sections, the following characteristic values and property relationships were evaluated: (a) strength and MOE in bending, (b) in-grade characteristic values of bending strength, bending MOE and density, (c) relationship of characteristic values of tension and compression strength parallel to the grain with respect to the corresponding characteristic value of bending strength, (d) ratio of fifth percentiles and mean values of density and MOE, as well as (e) the ratio of $\mathrm{MOE}$ in bending, tension and compression. Mechanical tests were accompanied by measurements of density and ultrasonic wave speed. Resulting dynamic MOE was partly used as an indicator of timber quality.
\end{abstract}

R. Steiger $(\varangle) \cdot$ M. Arnold

Empa, Swiss Federal Laboratories for Materials Testing and Research,

Wood Laboratory, Überlandstrasse 129, 8600 Dübendorf, Switzerland

e-mail: rene.steiger@empa.ch

M. Arnold

e-mail: martin.arnold@empa.ch 


\section{Introduction}

Solid timber for structural applications has to be strength graded prior to its use. Grading standards provide strength class systems to assign timber samples to specific strength classes. In order to remain simple and economic the grading process usually focuses on the most important physical and mechanical properties: density, modulus of elasticity parallel to the grain (MOE) and bending strength (MOR). To account for the variation of mechanical properties, the classification is based on so-called characteristic values, which are fifth percentile or mean values, respectively.

In Europe, the classification of structural timber is carried out according to a set of three linked standards:

- Test methods to determine mechanical properties as well as dimensions, moisture content (MC) and wood density of test pieces are specified in EN 408 (2003). The methods apply to rectangular and circular shapes of solid unjointed timber or finger-jointed timber and glued laminated timber with constant crosssections. The tests have to be carried out in dried conditions $\left(20^{\circ} \mathrm{C} / 65 \%\right.$ relative humidity).

- Characteristic values of mechanical properties and density are derived from the test data according to EN 384 (2004). The standard provides rules for sampling, analysing (e. g. calculating adjusted fifth percentiles weighted according to the number of specimens in each sample) and adjusting test values to geometrical or climatic properties differing from reference conditions given in EN 408.

- The timber is finally classified according to EN 338 (2003). This standard defines 12 strength classes for softwoods, prefixed C: C14, C16, C18, C20, C22, C24, C27, C30, C35, C40, C45, and C50 (Table 1). The numbers represent the characteristic bending strength $f_{m, k}$ for each strength class. A specific population can be assigned to a certain strength class if the characteristic values of density $r_{k}$ and bending strength $f_{m, k}$ (both of them are 5th-percentiles) as well as MOE (mean value, usually derived from bending tests) match or exceed the values of the desired class. Additional mechanical properties needed for the design of timber structures are derived from these basic values by empirical relationships.

\section{Relationship of bending strength and bending MOE}

Modulus of elasticity derived from bending tests correlates well with MOR. Coefficients of correlation $R$ up to $0.7-0.8$ are reported in the literature (Glos 1995). Since MOE can be derived by non-destructive tests, it is a very important parameter for machine grading. Most grading machines make use of MOE as an indicator for timber strength (Fewell 1982; Glos 1995). MOE can be determined either by static bending or dynamic methods (vibration, ultrasound) (Hearmon 1966; Kollmann and Krech 1960). 
Table 1 European strength class system for softwood species according to EN 338 (basic property values used for the classification are printed bold)

\begin{tabular}{|c|c|c|c|c|c|c|c|c|c|c|c|c|c|}
\hline \multirow{2}{*}{$\begin{array}{l}\text { Properties } \\
\left(\mathrm{N} / \mathrm{mm}^{2}\right)\end{array}$} & & \multicolumn{12}{|c|}{ Strength classes } \\
\hline & & $\mathrm{C} 14$ & C16 & $\mathrm{C} 18$ & $\mathrm{C} 20$ & $\mathrm{C} 22$ & $\mathrm{C} 24$ & $\mathrm{C} 27$ & C30 & $\mathrm{C} 35$ & $\mathrm{C} 40$ & $\mathrm{C} 45$ & $\mathrm{C} 50$ \\
\hline Bending & $f_{m, k}$ & 14 & 16 & 18 & 20 & 22 & 24 & 27 & 30 & 35 & 40 & 45 & 50 \\
\hline Tension ॥ & $f_{t, 0, k}$ & 8 & 10 & 11 & 12 & 13 & 14 & 16 & 18 & 21 & 24 & 27 & 30 \\
\hline Compression ॥ & $f_{c, 0, k}$ & 16 & 17 & 18 & 19 & 20 & 21 & 22 & 23 & 25 & 26 & 27 & 29 \\
\hline Mean MOE \| & $E_{0, \text { mean }}$ & 7,000 & 8,000 & 9,000 & $\mathbf{9 , 5 0 0}$ & 10,000 & 11,000 & 11,500 & 12,000 & 13,000 & 14,000 & 15,000 & 16,000 \\
\hline $\begin{array}{l}\text { 5th-percentile } \\
\text { of MOE ॥ }\end{array}$ & $E_{0,05}$ & 4,700 & 5,400 & 6,000 & 6,400 & 6,700 & 7,400 & 7,700 & 8,000 & 8,700 & 9,400 & 10,000 & 10,700 \\
\hline Mean density & $r_{\text {mean }}$ & 350 & 370 & 380 & 390 & 410 & 420 & 450 & 460 & 480 & 500 & 520 & 550 \\
\hline $\begin{array}{c}\text { 5th-percentile } \\
\text { of density }\end{array}$ & $r_{k}$ & 290 & 310 & 320 & 330 & 340 & 350 & 370 & 380 & 400 & 420 & 440 & 460 \\
\hline
\end{tabular}

Simultaneous matching of in-grade characteristic values of MOR, mean MOE and density

In practical design of timber structures, MOR and MOE are important parameters, the latter being of even more importance since deformations of structural elements are often decisive in the course of the design process (Thelandersson 1995). Compressive strength parallel to the grain as well as embedding strength has been reported to correlate with density (Ehlbeck and Werner 1992; Fewell 1982; Gindl and Teischinger 2002; Kollmann and Côté 1968). Therefore, EN 338 assigns a timber population to a strength class, if its characteristic values of bending strength and density (fifth percentiles) and its characteristic mean modulus of elasticity in bending equals or exceeds the limits for that respective strength class (Table 1). Hence, it is of utmost importance that within all grades, these three basic values match as good as possible. If, for example, a specific population which fulfils the criterion for MOR and MOE has to be graded down to a lower class because the density values are not reached, it has to be questioned if density limits are set correctly.

Ratio of tensile and compression strength parallel to the grain to bending strength

Both parallel-to-the-grain tensile and compression strength are used when designing axially loaded timber members. Respective characteristic values $f_{t, 0, k}$ and $f_{c, 0, k}$ in EN 338 (Table 1) are derived from characteristic MOR $f_{m, k}$ using empirical relationships.

According to EN 384 (2004) the characteristic values of tensile strength parallel to the grain $f_{t, 0, k}$ for softwood species can be calculated with Eq. (1):

$$
f_{t, 0, k}=0.6 f_{m, k}
$$

This constant ratio is used in most strength class systems for structural timber (Green and Kretschmann 1990), although it was shown in several studies not to 
be constant but rather to depend on timber quality. Burger and Glos (1997) found a noticeable effect of both grading method and dimensions on the $f_{t} / f_{m}$ ratio. The ratio $f_{t} / f_{m}$ rises with increasing timber quality and thus with increasing strength. Burger and Glos (1997) reported a $f_{t} / f_{m}$ ratio of 0.69 for the fifth percentile level while the ratio on the 50th-percentile level was found to be 0.76 . In the course of their discussion of timber property relationships in Eurocode 5, Green and Kretschmann (1989) compared ultimate bending strength and tensile strength parallel to the grain for in-grade data resulting from tests of different softwood species (Douglas fir, larch, Hemlock and Southern pine). For values of ultimate tensile strength up to $55 \mathrm{~N} / \mathrm{mm}^{2}$ the average ratio was $f_{t, 0, k} / f_{m, k}=0.59$. Above that limit, the ratio increased slightly. The authors, however, suggested retaining Eq. (1).

Furthermore, EN 384 gives Eq. (2) to derive the characteristic values of compression strength parallel to the grain $f_{c, 0, k}$ for softwood species from the corresponding bending strength $f_{m, k}$ :

$$
f_{c, 0, k}=5\left(f_{m, k}\right)^{0.45}
$$

For in-grade tested Douglas fir-larch, Hem-fir and Southern pine, Green and Kretschmann (1989) found the trend of the relationship to be virtually identical to the data presented by Curry and Fewell (1977), which forms the basis of Eq. (2) above. However, in earlier (Ylinen 1942) and recent (Ruli 2004) publications a strong correlation between compression strength parallel to the grain and wood density is reported.

Ratio of fifth percentiles and mean value of density and MOE

Since density correlates well with compression strength (parallel as well as perpendicular to the grain) and embedding strength, respective characteristic values can be derived from this basic property. Strength values normally are fifth percentiles and thus these values have to be based in the fifth percentile of density. In EN 338, the in-grade characteristic value of density is derived from the grade's mean value assuming a specific coefficient of variation (COV). The ratio of the characteristic to the mean value of density given in EN 338 varies between 0.82 and 0.85 with an average of 0.84 (Table 1). This variation results from rounding. Former versions of EN 384 explicitly assumed a constant ratio of 0.84 for softwood species, which in case of a normally distributed sample is identical to a COV of $10 \%$. Green and Kretschmann (1989) reported an average ratio of 0.80 with a range of 0.78 to 0.83 for three major species groups (Douglas Fir-Larch, Hem-Fir and Southern Pine). The average ratio for all species was 0.83 .

Fifth percentile of MOE $E_{0,05}$ is used in calculations where member stiffness takes direct influence on member strength, e. g. overall structural stability, buckling and lateral torsional stability. EN 384 and EN 338 assume a constant ratio of fifth percentile $\left(E_{0,05}\right)$ and mean value $\left(E_{0, \text { mean }}\right)$ of MOE (Table 1$)$ : 


$$
E_{0,05} / E_{0, \text { mean }}=0.67 \text { for softwood species }
$$

For infinite sized normally distributed samples, this fractile ratio corresponds to a COV of $20 \%$. Green and Kretschmann (1989) suggested to lower the ratio and to make it a function of strength class.

Ratio of MOE in bending, tension and compression parallel to the grain

Most investigations on the ratio between the moduli of elasticity were carried out with small clear specimens (Conners and Medvecz 1992). Clear specimens exhibit identical tensile and compression MOE (Thunell 1941). Garfinkel (1973) developed his wooden beam analysis on the assumption that the ratio of tension MOE to compression MOE is between 1.00 and 1.05. Kollmann and Côté (1968) expected the ratio to be approximately 1.00 for softwood. For sugar maple and basswood, Schneider and Phillips (1991) found different parallel-to-the-grain MOE values in bending, tension and compression. Burger and Glos (1995) showed that the MOE in tension and in bending of full-size spruce structural timber, in contrast to small clear specimens, depends on the type of load as well as on timber quality. The authors evaluated test results of 147 European spruce specimens dimensioned 50/120 $\mathrm{mm}^{2}$ (54 specimens) and 60/105 $\mathrm{mm}^{2}$ (93 specimens). On average, bending MOE $E_{m}$ was $9 \%$ higher than the tensile MOE $E_{t}$ and the following regression Eq. (4) was reported:

$$
E_{m}=90+1.077 E_{t}\left[\mathrm{~N} / \mathrm{mm}^{2}\right] \text { with } R=0.94
$$

EN 338 does not make any difference in MOE depending on the type of loading (bending, tension, compression) and gives one single value $E_{0}$ (Table 1). If the differences between $E_{m}, E_{t}$ and $E_{c}$ for timber in structural sizes actually are small, assigning one single MOE value is a good solution, since the process of designing timber structures can be kept simple.

Aim of the study

Correct property relationships are very important for the design of economic and reliable timber structures. The objective of this study was to review some of these property relationships based on recently compiled large data sets as a contribution for a future revision of the grading standards. Based on several series of tests with Norway spruce structural timber, the following property relationships were analysed:

- relationship of bending strength and bending MOE,

- simultaneous matching of in-grade basic characteristic values MOR $f_{m, k}$, mean MOE (derived from bending tests) $E_{0 \text {,mean }}$ and density $r_{k}$,

- ratio of characteristic tensile and compression strength parallel to the grain $f_{t, 0, k}$ and $f_{c, 0, k}$ to characteristic bending strength $f_{m, k}$,

- ratio of 5th-percentiles and mean values of density $r$ and MOE $E_{0}$,

- ratio of MOE in bending $E_{m}$, tension $E_{t, 0}$ and compression $E_{c, 0}$. 


\section{Materials and methods}

\section{Data sets}

Three data sets from different extensive research projects, referenced (1) to (3) served as data base:

1. In the early 1990 s a test program was launched at the ETH Zurich, which aimed to evaluate the mechanical properties of Swiss grown Norway spruce structural timber (Steiger 1995a, b, 1996).

2. The second source of data is a research project started after the extraordinarily violent winter storm 'Lothar' in Central Europe in December 1999, aiming at collecting more information regarding the extent and location, the causes, the detection, and the consequences of wind-induced compression failures (Arnold and Steiger 2007). Property relationship analysis of this data source, however, was only carried out using data resulting from reference tests on samples without any storm damages.

3. A third source of data is a Ph.D. thesis (Mischler-Schrepfer 2000) dealing with the influence of long-term log storage in the forest on the mechanical properties of timber.

In order to get large sample sizes, the data taken from the above mentioned studies were pooled for the different analysis steps (Tables 2, 3, 4):

(A) Data set (A) (Table 2) consisted of bending test data (MOE $E_{m}$ and MOR $f_{m}$ ) of 696 specimens of cross-section b/h (mm): 60/120, 80/160, 100/160 and 95/110.

(B) In data set (B) (Table 3) results from 796 tension tests (MOE $E_{t, 0}$ and tension strength $f_{t, 0}$ ) were pooled. The dimensions of the specimens covered a broad range from plank-type specimens to squared timber.

(C) Due to the fact that compression tests were not treated with the same priority within project (1), the compression data pool (C) (Table 4) was smaller $\left(n_{\mathrm{tot}}=152\right)$ than data sets (A) and (B). However, since variation of test values is smaller compared to the tension and bending tests, this is no problem for the data analysis.

Table 2 Data pool (A): specimens tested in edgewise bending (see Fig. 2a)

\begin{tabular}{llclll}
\hline Source & $\begin{array}{l}\text { Cross-section } \\
b / h(\mathrm{~mm})\end{array}$ & $\begin{array}{l}\text { Sample } \\
\text { size } n\end{array}$ & Span $\ell(\mathrm{mm})$ & $\begin{array}{l}\text { Distance between } \\
\text { loading points } \\
\ell-2 a(\mathrm{~mm})\end{array}$ & $\begin{array}{l}\text { Gauge length } \\
\ell_{1}(\mathrm{~mm})\end{array}$ \\
\hline 1 & $60 / 120$ & 53 & $2,160=18 h$ & $720=6 h$ & $500=4.17 h$ \\
& $80 / 160$ and 100/160 & $244^{\mathrm{a}}$ & $2,700=16.88 h$ & $900=5.62 h$ & $600=3.75 h$ \\
& $80 / 160$ & 36 & $2,760=17.25 h$ & $920=5.75 h$ & $600=3.75 h$ \\
2 & $95 / 110$ & 363 & $1,980=18 h$ & $660=6 h$ & $550=5 h$ \\
$n_{\text {tot }}$ & & 696 & & & $5 h$ \\
EN 408 specifications & & $18 h$ & $6 h$ & \\
\hline
\end{tabular}

\footnotetext{
${ }^{\text {a }}$ Proof loaded sample with 214 MOE and density values and 88 bending strength values
} 
Table 3 Data pool (B): specimens tested in tension parallel to the grain (see Fig. 2b)

\begin{tabular}{llcll}
\hline Source & Cross-section $b / h(\mathrm{~mm})$ & Sample size $n$ & Free length $\ell_{F}(\mathrm{~mm})$ & Gauge length $\ell_{M}(\mathrm{~mm})$ \\
\hline 1 & $10 / 180$ & 7 & $910-1,220=5.06-6.78 h$ & $900=5 h$ \\
& $20 / 180$ & 50 & $1,640=9.11 h$ & $900=5 h$ \\
$30 / 180$ & 21 & $1,640=9.11 h$ & $900=5 h$ \\
$40 / 180$ & 34 & $1,640=9.11 h$ & $900=5 h$ \\
$30 / 150$ & 40 & $1,620=10.80 h$ & $900=6 h$ \\
$80 / 80$ & 46 & $1,200=15 h$ & $900=11.25 h$ \\
& $80 / 120$ & $1,200=10 h$ & $900=7.50 h$ \\
& $80 / 160$ & $1,100=6.88 h$ & $900=5.63 h$ \\
& $80 / 180$ & 21 & $1,200=6.67 h$ & $900=5 h$ \\
2 & 42 & $1,200=6.67 h$ & $900=5 h$ \\
3 & $45 / 180$ & 104 & $4,300=28.67 h$ & $750=5 h$ \\
& $29 / 150$ & 126 & $3,300=22 h$ & $750=5 h$ \\
& $45 / 150$ & 156 & $3,300=22 h$ & $750=5 h$ \\
$n_{\text {tot }}$ & $49 / 150$ & 109 & $3,300=22 h$ & $750=5 h$ \\
EN 408 specifications & 796 & & $5 h$ \\
\hline
\end{tabular}

Table 4 Data pool (C): specimens tested in compression parallel to the grain (see Fig. 2c)

\begin{tabular}{llllll}
\hline Source & $\begin{array}{l}\text { Cross-section } \\
b / h(\mathrm{~mm})\end{array}$ & $\begin{array}{l}\text { Sample } \\
\text { size } n\end{array}$ & $\begin{array}{l}\text { Length } \\
\ell(\mathrm{mm})\end{array}$ & $\begin{array}{l}\text { Free length } \\
0.5 \ell(\mathrm{mm})\end{array}$ & $\begin{array}{l}\text { Gauge length } \\
\ell_{M}(\mathrm{~mm})\end{array}$ \\
\hline 1 & $60 / 120$ & 46 & $1,000=8.33 h$ & $500=8.33 b$ & $600=10 \mathrm{~b}$ \\
& $80 / 160$ & 19 & $1,500=9.38 h$ & $750=9.38 b$ & $900=11.25 b$ \\
& $100 / 160$ & 40 & $1,500=9.38 h$ & $750=7.50 b$ & $900=9 b$ \\
& $140 / 240$ & 47 & $1,500=6.25 h$ & $750=5.36 b$ & $700=5 b$ \\
& & 152 & & & \\
$n_{\text {tot }}$ & & - & $6 b$ & \\
EN 408 specifications: & & & & & \\
\hline
\end{tabular}

(D) The data needed for the comparison of MOE in bending, tension and compression were collected in the course of interaction tests on 80/160 mm beams simultaneously loaded by a bending moment and a normal (tension or compression) force (Steiger and Fontana 2005) being part of project (1) (Steiger 1995b). Sample size amounted to 109 pairs of values $\left(E_{m} ; E_{t}\right)$ and 81 pairs of values $\left(E_{m} ; E_{c}\right)$. All specimens were cut according to the sawing pattern shown in Fig. 1. 
Fig. 1 Sawing pattern of interaction test specimens $(80 / 160 \mathrm{~mm})$

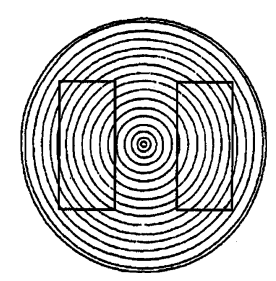

\section{Test procedures}

All three studies (1)-(3) used similar test procedures (Tables 2, 3, 4). Testing was carried out in accordance with EN 408 (2003) and the characteristic values were determined according to EN 384 (2004). The critical section was always positioned in such way that it was subjected to maximum load.

Moisture content was measured by the electric resistance method. Density was determined from the mass and the volume of the whole specimen. The "global" density values were adjusted to the density of small defect-free prisms (ISO 3131 1975) by dividing by 1.05 given in EN 384 .

Tests to derive bending MOE and bending strength were performed in edgewise position. The tension edge was selected at random. The test pieces, having a minimum length of approximately 19 times the depth of the section, were simply supported and symmetrically loaded in bending at two points over a span of approximately 18 times the depth. MOE was measured within the loading points. In the course of project (1), the concept of proof loading with a threshold of $40 \mathrm{~N} / \mathrm{mm}^{2}$ was used, resulting in 214 values of bending MOE but in only 88 bending strength values. With respect to notations in Fig. $2 \mathrm{a}$ and d, Table 2 lists geometrical properties of bending tests carried out.

Tension tests parallel to the grain were carried out according to EN 408, the timber being of full cross-section (Fig. 2d). Geometrical properties of specimens subjected to tension tests are presented in Table 3 with notations according to

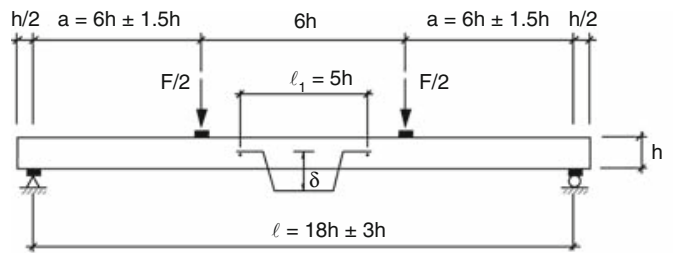

(a)

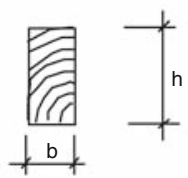

(d)

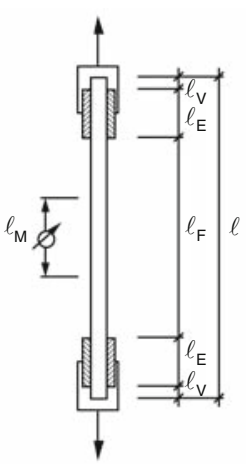

(b)

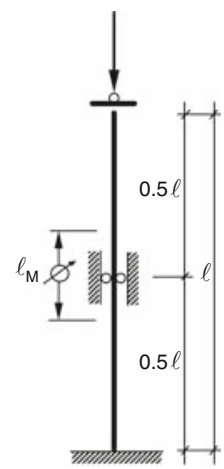

(c)

Fig. 2 Test configurations to perform bending (a) and parallel-to-the-grain tension (b) and compression tests (c). All specimens were of rectangular cross-section $b / h(\mathbf{d})$ 
Fig. 2b. Tests were carried out with special test equipment set up and optimised based on preliminary studies presented in (Steiger et al. 1994).

Compression tests were carried out with lateral restraints at half-length to prevent the specimens from buckling (Fig. 2c). Geometrical properties of the specimens are listed in Table 4.

\section{Assessment of timber quality}

The MOE, although not being a direct parameter to define strength, but depending on the same factors, is the best single indicator of timber quality (Glos 1995). Instead of the static MOE, dynamic MOE $E_{\text {dyn }}$ was used as a reference indicator of quality. $E_{\mathrm{dyn}}$ was calculated from the velocity $v$ of an ultrasonic wave passing the specimen longitudinally and from the specimen's density $r$ [Eq. (5)]. Such measurements, originally described by Goens (1931), are successfully used for assessing the quality of structural timber (Hearmon 1966; Kollmann and Krech 1960).

$$
E_{\mathrm{dyn}}=r v^{2}
$$

Equation (5) is valid if the wave length is bigger than the lateral dimensions of the specimens. For Norway spruce timber typical ultrasonic wave velocities are in the range of 5,000-6,000 m/s, resulting in wave lengths between approximately 15 and $40 \mathrm{~cm}$.

The longitudinal ultrasonic wave velocity was determined from specimen length and travel time of the signal. The ultrasonic testers Steinkamp BP V (frequency $=50 \mathrm{kHz}$ ) and Sylvatest (frequency $=16 \mathrm{kHz}$ ) were used. To account for the influence of moisture on the ultrasonic wave velocity, Eq. (6) (Sandoz 1990) and (7) were used. Equation (7) is a linearization of (6), which for different MCs (MC1, MC2) between 10 and $20 \%$ is equal to Eq. (6).

$$
\begin{gathered}
v_{1}=\frac{v_{2}}{[1-0.0053(\mathrm{MC} 2-\mathrm{MC} 1)]} \quad \text { for } \mathrm{MC}<28 \% \\
v_{1}=v_{2}+29(\mathrm{MC} 2-\mathrm{MC} 1) \quad \text { for } \mathrm{MC}<28 \%
\end{gathered}
$$

\section{Data processing}

According to EN 384, characteristic values (sample fifth percentiles) are to be estimated by determining the fifth percentiles of ranked samples. However, with regard to in-grade samples of usually smaller size, the analysis to calculate fifth percentiles used parametric methods to take into account all the information provided by the test results. In case of strength variables, a lognormal distribution was used. MOE and density data were analysed assuming normal distributions.

Dynamic MOE $E_{\mathrm{dyn}}$ was used to group test values according to timber quality. Grouping always aimed to get at least 40 specimens in each group. Usually, groups contained more than 60-80 specimens.

According to EN 384, the reference wood moisture content shall be consistent with $20^{\circ} \mathrm{C}$ and $65 \%$ relative humidity, which for most softwood corresponds to a 
MC of about $12 \%$. For samples not tested at reference conditions but having a mean $\mathrm{MC}$ in the range of 10 to $18 \%$, adjustment of lower fifth percentile or mean values to $12 \% \mathrm{MC}$ was made according to EN 384 as follows:

- for bending and tensile strength: no adjustment

- for compression parallel to the grain strength: $3 \%$ change for every percentage point difference in $\mathrm{MC}$

- for MOE: $2 \%$ change for every percentage point difference in MC

The adjustments were carried out in a way that the above-quoted properties increase if the data are adjusted from a higher MC, and vice versa.

For bending strength, the reference dimensions correspond to a depth (height) $h$ of $150 \mathrm{~mm}$ and to the standard test set-up proportions of four point bending with loads applied in the third points and an overall span of 18 times the specimen depth $h$. Tensile strength is given for a reference width $h$ of $150 \mathrm{~mm}$. For samples not tested at reference conditions, EN 384 gives adjustment factors. Size adjustment to $150 \mathrm{~mm}$ depth or width can be made by dividing the fifth percentile by $k_{h}$ [Eq. (8)]:

$$
k_{h}=\left(\frac{150}{h}\right)^{0.2}
$$

Tensile strength data resulting from tests with different lengths $\ell_{\mathrm{et}}$ can be adjusted to reference length $\ell_{\mathrm{es}}$ by using Eq. (9) with an exponent of $m_{\ell}=0.15$.

$$
k_{\ell}=\left(\frac{\ell_{\mathrm{es}}}{\ell_{\mathrm{et}}}\right)^{m_{\ell}}
$$

\section{Results and discussion}

Timber quality

Dynamic MOE $E_{\text {dyn }}$, which can be measured non-destructively, is a good indicator of actual stiffness (MOE) and strength of timber in bending, tension and compression as shown in Fig. 3. Figures $3 \mathrm{a}-\mathrm{c}$ confirm a strong correlation $(R=0.77-0.90)$ between static and dynamic MOE. Hence, it can be concluded that MOE can be derived by a much simpler dynamic measurement together with density instead of carrying out static bending tests. Regarding machine grading, dynamically measuring MOE provides the only possibility of grading timber members with thickness of more than $75 \mathrm{~mm}$, since most stress grading machines with static MOE measurements are limited to member thicknesses up to $75 \mathrm{~mm}$.

According to Fig. 3d-f the correlation between dynamic MOE and bending, parallel-to-the-grain compression and tensile strength is weaker $(R=0.59-0.72)$. However, the correlation still is strong enough to use dynamic MOE as one of the indicators for timber strength when equipping grading machines or when assigning experimental data to given strength classes. 
(a)

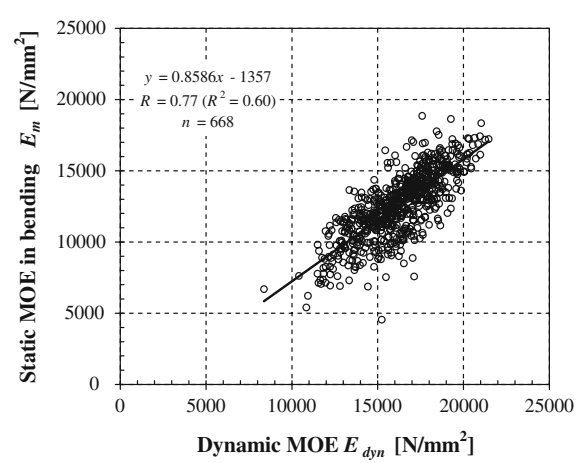

(b)

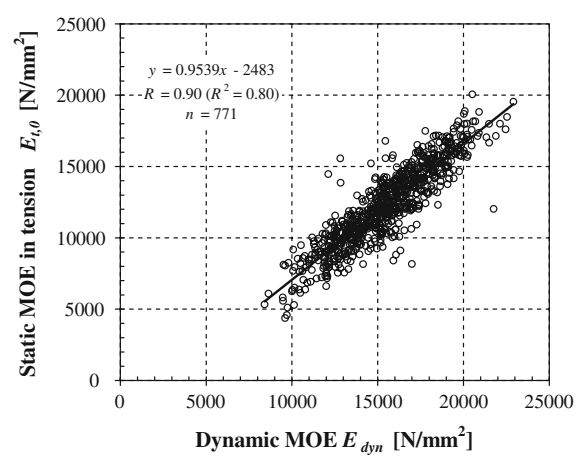

(c)

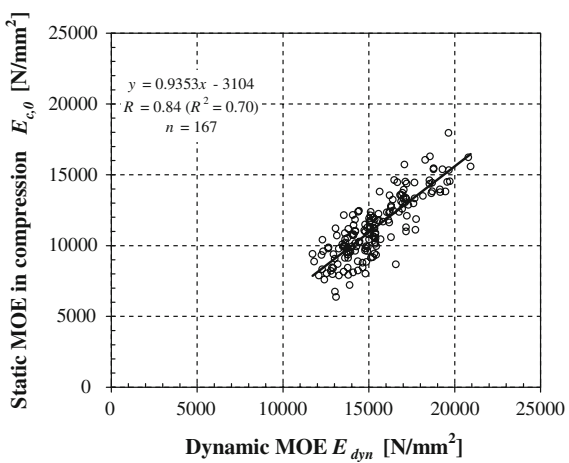

(d)

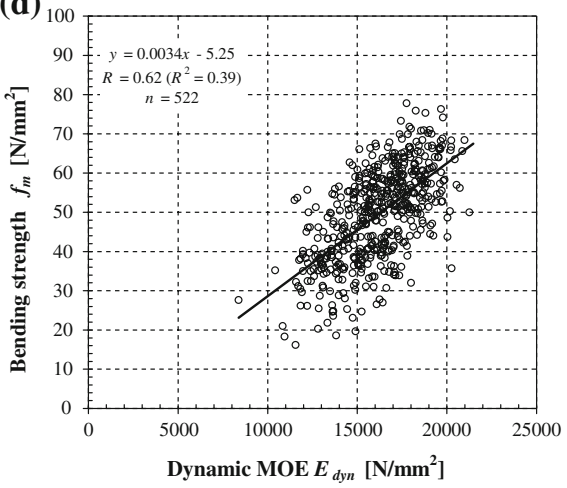

(e)

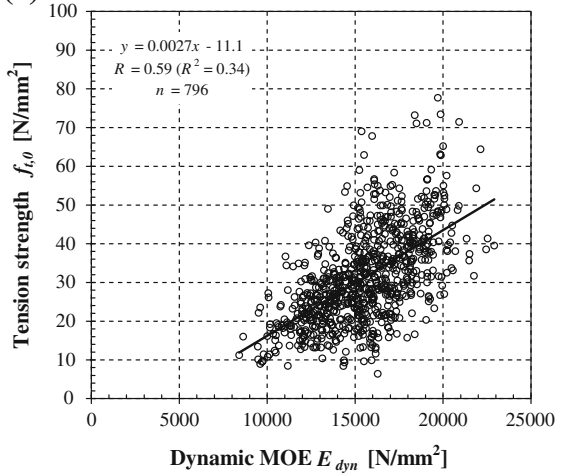

(f)

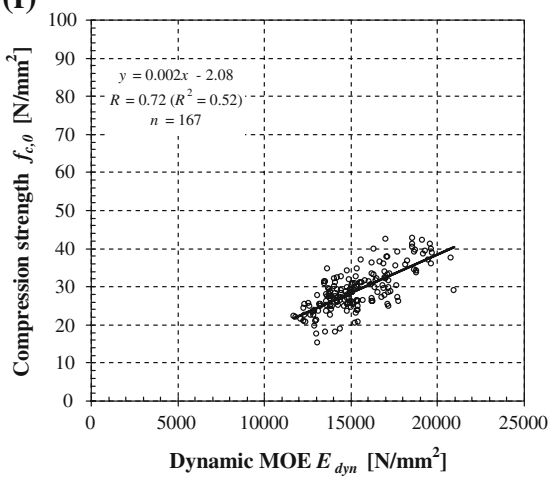

Fig. 3 Correlation of dynamic MOE $E_{\mathrm{dyn}}$ with MOE in bending $E_{m}(\mathbf{a})$, tension $E_{t, 0}(\mathbf{b})$, compression $E_{c, 0}$ (c) and with bending strength $f_{m}(\mathbf{d})$, tensile strength $f_{t, 0}(\mathbf{e})$ and compression strength $f_{c, 0}(\mathbf{f})$

Relationship of bending strength and bending MOE

The correlation between bending strength $f_{m}$ and bending MOE $E_{m}$ derived from static bending tests is shown in Fig. 4. The coefficient of correlation amounts to 
$R=0.66$, which is lower compared to other studies reported in Glos (1995). The EN 338 basic strength class values (characteristic bending strength $f_{m, k}$ and MOE parallel to the grain $E_{0 \text {,mean }}$ ) follow the trend of the experimental data up to strength class C24 $\left(f_{m, k}=24 \mathrm{~N} / \mathrm{mm}^{2}\right)$. In strength classes C27-C50 $\left(f_{m, k}=27\right.$ to $\left.50 \mathrm{~N} / \mathrm{mm}^{2}\right)$, the bending MOE found in our tests is higher than the assigned strength class value. The reason for this is not clear and no answer could be found in background documents of the standard and in the corresponding literature. Assigning lower MOE in strength classes for high-performance timber might, however, be a hidden additional safety intended by the responsible standardisation committee.

Simultaneous matching of in-grade basic characteristic values of MOR, mean MOE and density

In order to assign a sample to a certain strength class provided by EN 338, the characteristic values (fifth percentiles) of bending strength $f_{m, k}$ and density $r_{k}$ as well as the mean MOE parallel to the grain $E_{0 \text {,mean }}$ have to match or exceed the class values. The data set derived from bending tests (sample size $n=522$ ) was divided into six equally sized groups according to measured dynamic MOE $E_{\mathrm{dyn}}$. The above-mentioned characteristic values were calculated for each group and compared to the code values given in EN 338. Figure 5 shows that the test data match the strength class profile given by EN 338 very well. For strength classes with $\mathrm{MOE}>13,000 \mathrm{~N} / \mathrm{mm}^{2}$ the tests exhibit somewhat higher MOE values than assigned by EN 338. Hence, based on the tests results described in this study, there is no reason for changing in-grade discrimination of basic characteristic values $f_{m, k}, E_{0 \text {,mean }}$ and $r_{k}$.

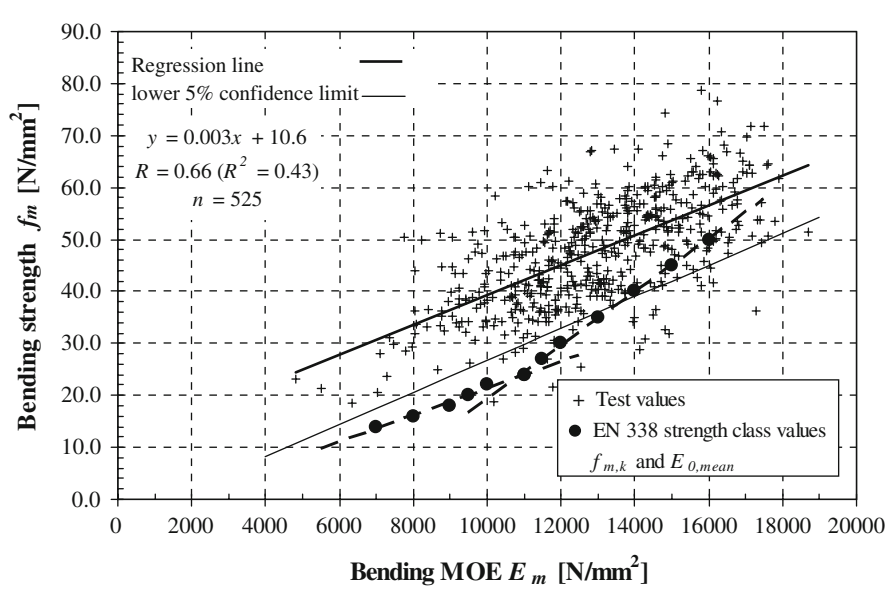

Fig. 4 Bending strength $f_{m}$ versus bending MOE $E_{m}$ derived by static tests (edgewise). The dots indicate pairs of $\left(f_{m, k} ; E_{0, \text { mean }}\right)$ given in EN 338 (Table 1) 


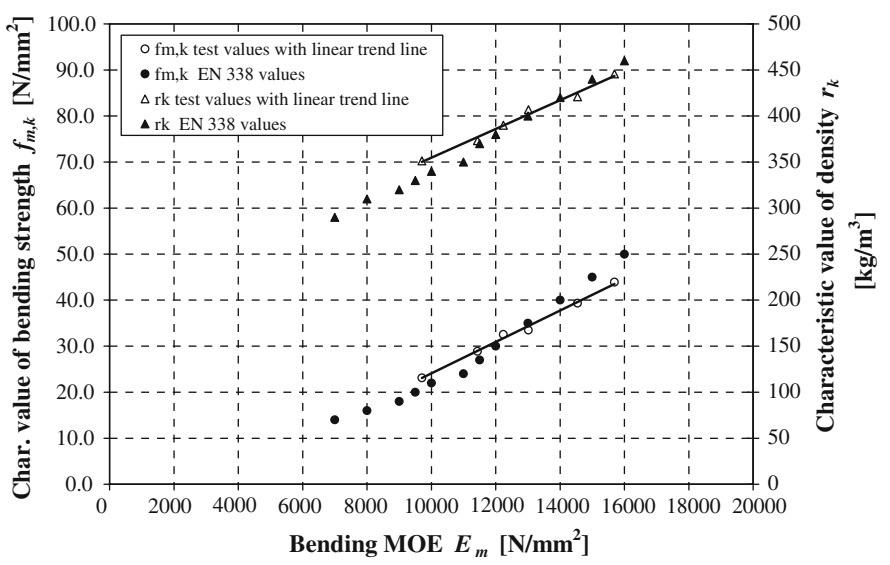

Fig. 5 Comparison of EN 338 basic strength class values $f_{m, k}, E_{0, \text { mean }}$ and $r_{k}$ (Table 1) and test values (with linear trend lines)

Ratio of tensile and compression strength parallel to the grain to bending strength

A direct comparison of bending and tensile or compression strength is not possible since one cannot test the same specimen to failure in bending and in tension or compression, respectively. The ratio of characteristic values of tensile strength $f_{t, 0, k}$ to bending strength $f_{m, k}$ shown in Fig. 6a was therefore derived from data grouped according to the dynamic MOE $E_{\mathrm{dyn}}$ with equal class boundaries for both bending and tensile strength data sets (five groups). The relationship of tensile and bending strength on the mean as well as on the fifth percentile level is shown in Fig. $6 \mathrm{~b}$ together with linear trend lines. The ratio of tensile to bending strength obviously is not constant but rather depends on timber quality. Ratios of mean values and characteristic values exhibit the same trend. Assuming a constant ratio of $f_{t} / f_{m}=0.6$ according to Eq. (1) gives safe results for characteristic bending strength values $f_{m, k} \geq 22 \mathrm{~N} / \mathrm{mm}^{2}$ (EN 338 strength classes C22 and higher). For $f_{m, k}<22 \mathrm{~N} / \mathrm{mm}^{2}$, however, the ratio derived from the test results is smaller than 0.6. Hence, it is suggested to analyse other data sets, in order to get reliable information on ratios of tensile to bending strength for strength classes lower than C22.

The ratio of characteristic values of compression strength $f_{c, 0, k}$ to bending strength $f_{m, k}$ shown in Fig. 7a was derived from data grouped again according to the dynamic MOE $E_{\mathrm{dyn}}$ with equal class boundaries for both bending and compression strength data sets (four groups). The relationship of compression and bending strength on the mean as well as on the fifth percentile level is shown in Fig. 7b together with power trend lines. Compared to our test results the EN approach [Eq. (2)] is more conservative for characteristic bending strength values $f_{m, k} \geq 24 \mathrm{~N} / \mathrm{mm}^{2}$ (EN 338 strength classes $\geq \mathrm{C} 24$ ). The trend line fitting the test results progresses equally on the mean and on the characteristic level. An extrapolation of the trend to 
(a)

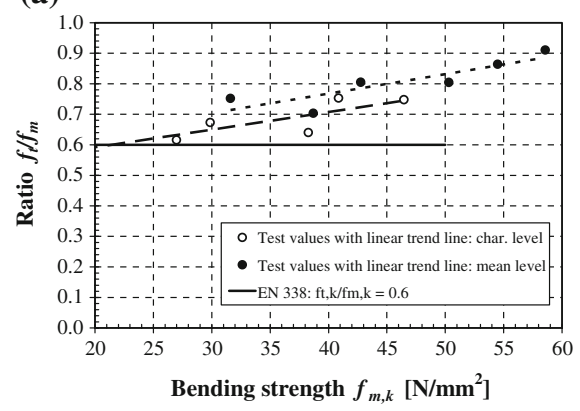

(b)

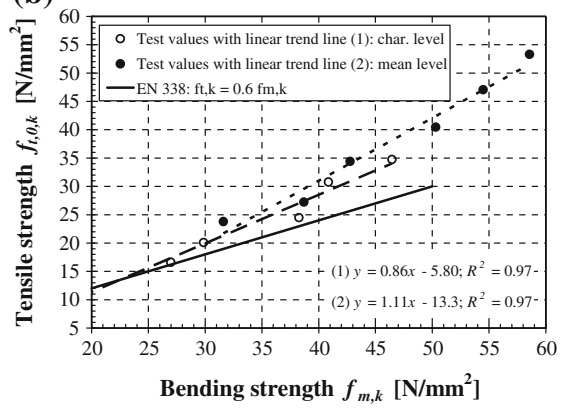

Fig. 6 Ratio (a) and relationship (b) of bending strength $f_{m}$ and tensile strength $f_{t}$

characteristic bending strengths $f_{m, k}<24 \mathrm{~N} / \mathrm{mm}^{2}$, however, results in lower $f_{c, 0, k}$ values compared to the characteristic values assigned by Eq. (2) and thus Eq. (2) overestimates $f_{c, 0, k}$ in strength classes lower than C24.

EN 338 values as well as test values (four groups graded according to $E_{\mathrm{dyn}}$ ) exhibit a linear relationship between the compression strength parallel to the grain $f_{c, 0}$ and the wood density $r$ (Fig. 8). The slope of the regression line found in our tests, however, is almost twice the slope of the trend line fitted to the code values. This confirms again the overestimation of $f_{c, 0, k}$ by Eq. (2) for $\mathrm{f}_{c, 0, k}<20 \mathrm{~N} / \mathrm{mm}^{2}$. As an alternative to the code approach [Eq. (2)], the compression strength parallel to the grain could be derived from the wood density using a linear model.

Ratio of fifth percentile and mean value of density and MOE

The ratio between characteristic and mean value of density $(\mathrm{MC}=12 \%)$ of all 1,640 specimens results in $r_{k} / r_{\text {mean }}=0.84$. The mean value is $450 \mathrm{~kg} / \mathrm{m}^{3}$ and the

(a)

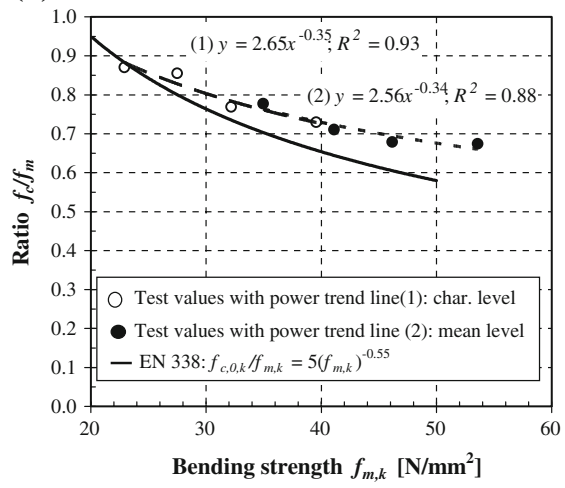

(b)

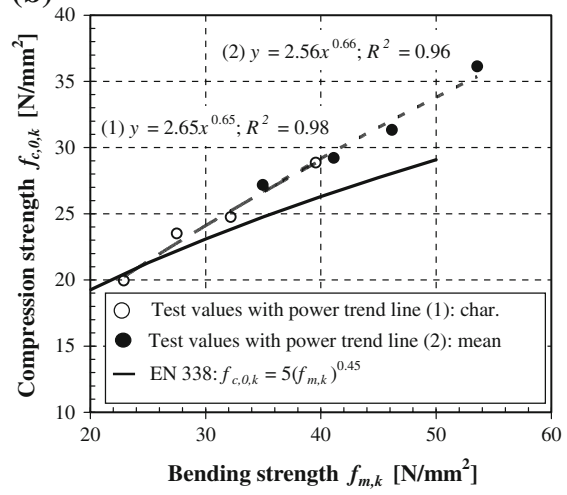

Fig. 7 Ratio (a) and relationship (b) of bending strength $f_{m}$ and compression strength $f_{c}$ 


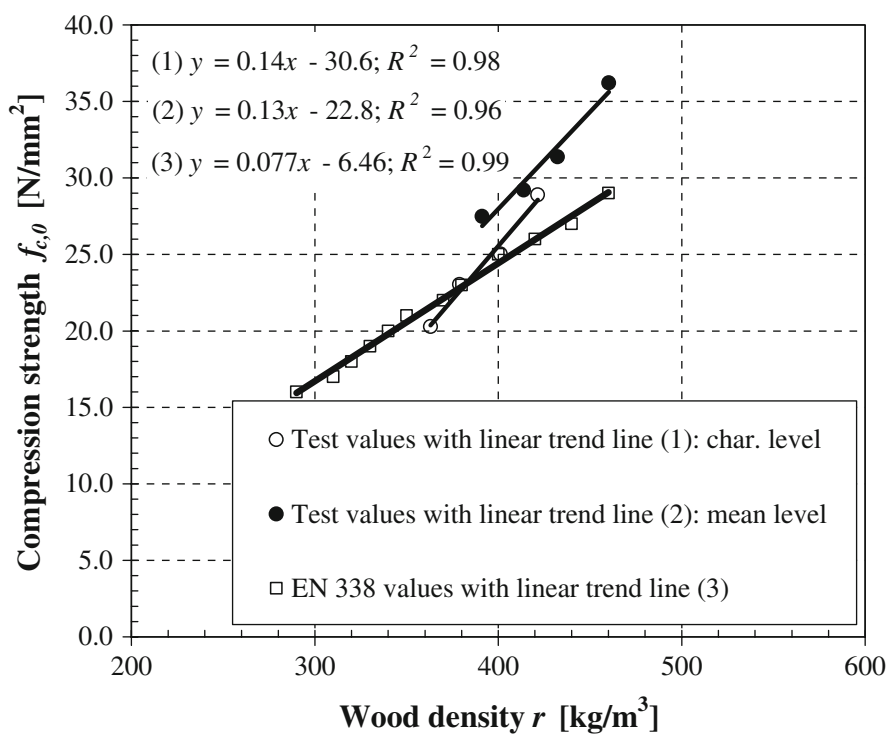

Fig. 8 Relationship between compression strength parallel to the grain $f_{c, 0}$ and wood density $r$ : Test results and EN 338 values (Table 1)

(a)

[\%]

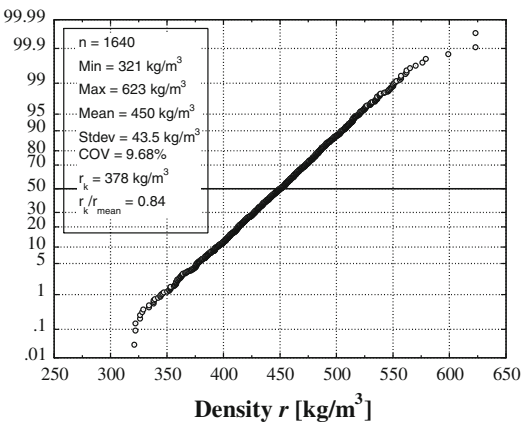

(b)

[\%]

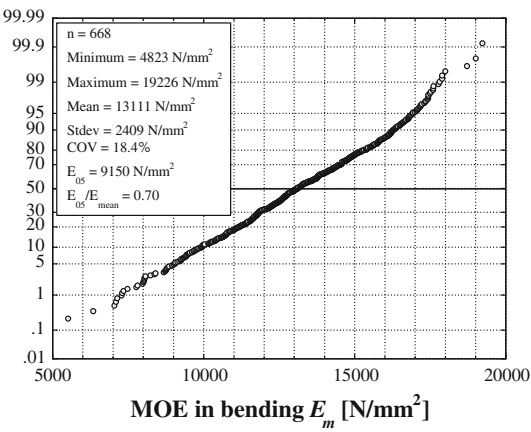

Fig. 9 Normal probability plot of density $r$ (a) and bending MOE $E_{m}(\mathbf{b})$ for a MC of $12 \%$

COV amounts to approximately 9.7\%. The normal probability plot (Fig. 9a) confirms the assumption of a normal distribution for density. The test results are in line with the code procedures of EN 338 and EN $384\left(\mathrm{COV}=10 \%\right.$ and ratio $r_{k}$ l $r_{\text {mean }}=0.84$ ).

The ratio of characteristic to mean MOE calculated based on all results of bending tests $(n=668)$ yields in $E_{05} / E_{\text {mean }}=0.70$. The $\operatorname{COV}$ is $18.4 \%$ and a normal distribution fits the data reasonably well (Fig. 9b). These results confirm the ratio and COV given in EN 338 and EN 384, which are 0.67 and 20\%, respectively. 
Ratio of MOE in bending, tension and compression

The relationships of bending MOE $E_{m}$ and tensile MOE $E_{t}$ or compression MOE $E_{c}$ are shown in Fig. 10. The following linear regression Eqs. (10) and (11) could be derived from the tests:

$$
\begin{aligned}
& E_{t}=0.808 E_{m}-2,523 \quad \text { with } R=0.91\left(R^{2}=0.83\right) \\
& E_{c}=0.745 E_{m}+3,357 \quad \text { with } R=0.85\left(R^{2}=0.72\right)
\end{aligned}
$$

Based on Eqs. (10) and (11), MOE values $E_{t}$ and $E_{c}$ and ratios $E_{t} / E_{m}$ and $E_{c} / E_{m}$ were calculated and compared to MOE values given in EN 338 for the whole strength class spectrum $\mathrm{C} 14$ to $\mathrm{C} 50$ (Table 5). Furthermore, the MOE ratios are plotted in Fig. 11. On average, bending MOE derived according to the EN 408 4-point bending test differed only by $1 \%$ from MOE in tension or in compression. However, the ratios are not constant; they depend on the timber quality:

- low-quality timber (for example class C18): $E_{t} / E_{m}=1.09 \quad E_{c} / E_{m}=1.12$

- normal-quality timber of classes C24-C30: $E_{t} / E_{m}=1.03 \quad E_{c} / E_{m}=1.04$

- high-quality timber of classes C35 and C40: $E_{t} / E_{m}=1.00 \quad E_{c} / E_{m}=1.00$.

Timber members assigned to classes C35 and C40 are free of defects. That is why such members behave similar to small clear specimens resulting in identical MOE $E_{t}, E_{c}, E_{m}$.

Looking at the process of designing timber structures, the practice of EN 338 of giving one single MOE value for each strength class is a good approach. However, when grading timber based on tension MOE instead of bending MOE, the differences reported above have to be taken into account. Then, timber has to be modelled as a composite material with zones of different MOE within cross-section (Gehri 1997).

(a)

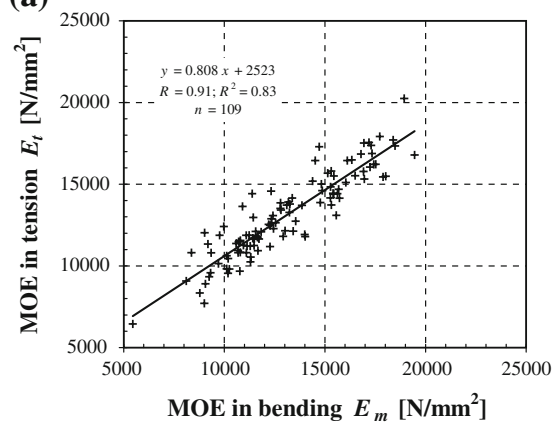

(b)

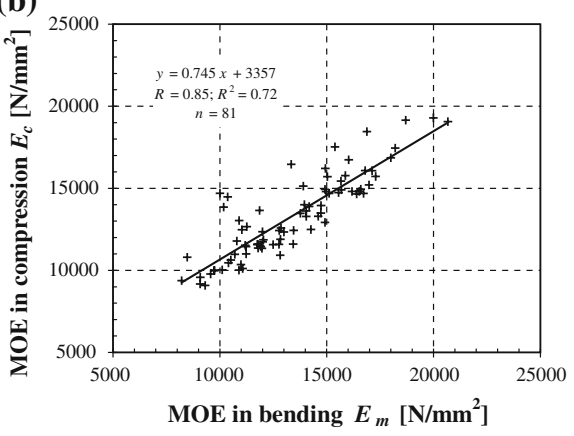

Fig. 10 Bending MOE $E_{m}$ versus MOE in tension $E_{t}(\mathbf{a})$ and in compression $E_{c}$ (b) for Norway Spruce structural timber with cross-section $80 / 160 \mathrm{~mm}$ 
Table 5 Ratios of bending MOE $E_{m}$ and MOE in tension $E_{t}$ or in compression $E_{c}$ for Norway spruce solid timber with cross-section $80 / 160 \mathrm{~mm}$

\begin{tabular}{llllll}
\hline Strength class & $\begin{array}{l}E_{m}\left(\mathrm{~N} / \mathrm{mm}^{2}\right) \\
\text { acc. to EN 338 }\end{array}$ & $\begin{array}{l}E_{t}\left(\mathrm{~N} / \mathrm{mm}^{2}\right) \\
\text { calc. with Eq. }(10)\end{array}$ & $\begin{array}{l}E_{c}\left(\mathrm{~N} / \mathrm{mm}^{2}\right) \\
\text { calc. with Eq. }(11)\end{array}$ & Ratio $E_{t} / E_{m}$ & Ratio $E_{c} / E_{m}$ \\
\hline C14 & 7,000 & 8,200 & 8,600 & 1.17 & 1.23 \\
C16 & 8,000 & 9,000 & 9,400 & 1.13 & 1.18 \\
C18 & 9,000 & 9,800 & 10,100 & 1.09 & 1.12 \\
C20 & 9,500 & 10,200 & 10,500 & 1.07 & 1.11 \\
C22 & 10,000 & 10,600 & 10,900 & 1.06 & 1.09 \\
C24 & $\mathbf{1 1 , 0 0 0}$ & $\mathbf{1 1 , 4 0 0}$ & $\mathbf{1 1 , 6 0 0}$ & $\mathbf{1 . 0 4}$ & $\mathbf{1 . 0 6}$ \\
C27 & $\mathbf{1 1 , 5 0 0}$ & $\mathbf{1 1 , 8 0 0}$ & $\mathbf{1 2 , 0 0 0}$ & $\mathbf{1 . 0 3}$ & $\mathbf{1 . 0 5}$ \\
C30 & $\mathbf{1 2 , 0 0 0}$ & $\mathbf{1 2 , 2 0 0}$ & $\mathbf{1 2 , 4 0 0}$ & $\mathbf{1 . 0 2}$ & $\mathbf{1 . 0 3}$ \\
C35 & 13,000 & 13,000 & 13,100 & 1.00 & 1.01 \\
C40 & 14,000 & 13,900 & 13,900 & 0.99 & 0.99 \\
C45 & 15,000 & 14,700 & 14,600 & 0.98 & 0.97 \\
C50 & 16,000 & 15,500 & 15,400 & 0.97 & 0.96 \\
\hline
\end{tabular}

Italic, extrapolation; bold, normal-quality timber

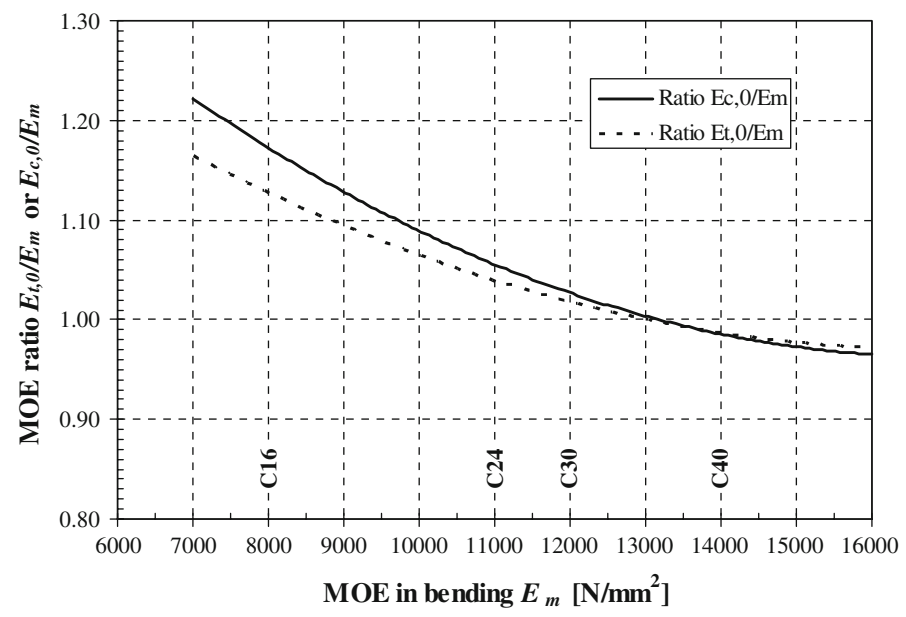

Fig. 11 MOE ratios: tension/bending and compression/bending

\section{Conclusion}

Our investigations lead to the following conclusions:

- Overall, the test results in this study confirm the property relationships and strength class profiles regarding bending strength, tension strength, compression strength, density and MOE given in EN 338. No reasons for substantial changes of these values were found. 
- The good correlation between dynamic MOE and static MOE (bending, tension, compression) as well as strength (MOR, tension and compression parallel to the grain) recommends using ultrasonic wave speed together with density as an indicator of timber quality.

- The coefficient of correlation of bending strength and bending MOE derived from static bending tests amounts to $R=0.66$ and is consistent with other studies and confirms limitation of strength prediction.

- Tensile to bending strength ratio was found not to be constant, but to depend on timber quality. Ratios for characteristic bending strengths $f_{m, k} \geq 22 \mathrm{~N} / \mathrm{mm}^{2}$ (EN 338 classes above $\mathrm{C} 22$ ) amounted to $0.6-0.75$ but were $<0.6$ for lower quality timber.

- The relationship between the characteristic values of compression and bending strength parallel to the grain given in EN 384 [Eq. (2)] is more conservative for higher quality timber than our test results indicate. As an alternative to the existing approach, the compression strength parallel to the grain could be derived from wood density using a linear model. Doing so, the importance of density as a classification criterion would be increased.

- The calculated fractile ratios for density $r_{k} / r_{\text {mean }}$ and for MOE parallel to the grain $E_{0,05} / E_{0 \text {,mean }}$ were 0.84 and 0.70 . These values correspond well to the ratios given in EN 384 and EN 338 (0.84 and 0.67) assuming a COV of 10\% and $20 \%$, respectively.

- The ratios of MOE of Norway spruce structural timber with a cross-section of $80 / 160 \mathrm{~mm}$ in tension, compression and bending differ depending on timber quality. Differences up to $9 \%$ between tensile and bending MOE were found. Regarding compression MOE, the maximum difference to the bending MOE was $12 \%$. For normal-quality timber of classes C24-C30 (mainly used in practice), the differences between $E_{t}, E_{c}$ and $E_{m}$ are not more than $6 \%$. With regard to a simple design process, the current practice of using one single MOE value should therefore not be changed. However, when assigning timber populations to strength classes based on tension MOE instead of bending MOE, the differences have to be taken into account. In this case, timber must be regarded as a composite material having zones of different MOE within crosssection.

\section{References}

Arnold M, Steiger R (2007) The influence of wind-induced compression failures on the mechanical properties of spruce structural timber. Mater Struct 40(1):57-68

Burger N, Glos P (1995) Relationship of moduli of elasticity in tension and in bending of solid timber. Paper 28-5-2. In: Proceedings of CIB-W18 Meeting 28, April 1995, Copenhagen, Denmark

Burger N, Glos P (1997) Strength relationships in structural timber subjected to bending and tension. Paper 30-6-1. In: Proceedings of CIB-W18 Meeting 30, August 1997, Vancouver, Canada

Conners TE, Medvecz PJ (1992) Wood as a bimodular material. Wood Fiber Sci 24(4):413-423 
Curry WT, Fewell AR (1977) The relations between the ultimate tension and ultimate compression strength of timber and its modulus of elasticity. Research Report CP22/77, Princes Risborough Laboratory, Building Research Establishment BRE, Buckinghamshire

Ehlbeck J, Werner H (1992) Coniferous and deciduous embedding strength for dowel-type fasteners. Paper 25-7-2. in: Proceedings of CIB-W18 Meeting 25, August 1992, Åhus, Sweden

EN 338 (2003) Structural timber-strength classes. Comité Européen de Normalisation CEN

EN 408 (2003) Timber structures-structural timber and glued laminated timber-determination of some physical and mechanical properties. Comité Européen de Normalisation CEN

EN 384 (2004) Structural timber : determination of characteristic values of mechanical properties and density. Comité Européen de Normalisation CEN

Fewell AR (1982) Machine Stress Grading of Timber in the United-Kingdom. Holz Roh Werkst 40(12):455-459

Garfinkel G (1973) Wood engineering. Southern Forest Products Association, New Orleans

Gehri E (1997) Timber as a natural composite: Explanation of some peculiarities in the mechanical behaviour. Paper 30-6-3. in: Proceedings of CIB-W18 Meeting 30, August 1997, Vancouver, Canada

Gindl W, Teischinger A (2002) Axial compression strength of Norway spruce related to structural variability and lignin content. Composites Part a. Appl Sci Manufact 33(12):1623-1628

Glos P (1995) Step A6: Festigkeitssortierung. In: Holzbauwerke nach Eurocode 5, Step 1: Bemessung und Baustoffe, Informationsdienst Holz. Arbeitsgemeinschaft Holz e. V, Düsseldorf, Germany

Goens E (1931) The determination of the elasticity module of rods with the help of bending fluctuations. Annalen der Physik 11(6):649-678

Green DW, Kretschmann DE (1989) A discussion of lumber property relationships in Eurocode 5. Paper 22-6-3. In: Proceedings of CIB-W18 Meeting 22, September 1989, Berlin, German Democratic Republic

Green DW, Kretschmann DE (1990) Stress class systems: an idea whose time has come? Research Paper FPL-RP-500. Forest Products Laboratory, Madison

Hearmon RFS (1966) Vibration testing of wood. Forest Prod J 16(8):29-40

ISO 3131 (1975) Wood; Determination of density for physical and mechanical tests. International organization for standardization

Kollmann F, Krech H (1960) Dynamische Messung der elastischen Holzeigenschaften und der Dämpfung. Holz Roh-Werkst 18(2):41-54

Kollmann FFP, Côté WA Jr (1968) Principles of wood science and technology, vol 1: solid wood. Springer, Berlin

Mischler-Schrepfer V (2000) Der Einfluss der Waldlagerung von Fichten-Rundholz auf die LängsZugeigenschaften des Schnittholzes, Ph.D. thesis, ETH Zürich, Switzerland

Ruli A (2004) Determination of the compression strength of glulam - longitudinal and perpendicular to the grain. Diploma thesis, Institute of Timber Engineering and Wood Technology, Graz University of Technology, Austria

Sandoz J-L (1990) Triage et fiabilité des bois de construction validité de la méthode ultrason, Lausanne, $\mathrm{Ph} . \mathrm{D}$. thesis, EPF Lausanne, Switzerland

Schneider MH, Phillips JG (1991) Elasticity of wood and wood polymer composites in tension, compression and bending. Wood Sci Technol 25(5):361-364

Steiger R (1995a) Biege-, Zug- und Druckversuche an Schweizer Fichtenholz, Institut für Baustatik und Konstruktion, ETH Zürich, Research Report Nr. 207, Birkhäuser Verlag, Basel, Switzerland

Steiger R (1995b) Versuche an Fichten-Kanthölzern: Biegemoment-Normalkraft-Interaktion, Institut für Baustatik und Konstruktion, ETH Zürich, Research Report Nr. 209, Birkhäuser Verlag, Basel, Switzerland

Steiger R (1996) Mechanische Eigenschaften von Schweizer Fichten-Bauholz bei Biege-, Zug-, Druckund kombinierter M/N-Beanspruchung, Research Report Nr. 221, Birkhäuser Verlag, Basel, Switzerland

Steiger R, Arm H, Gehri E (1994) Einspannvorrichtung für Zugversuche an Holzproben grösseren Querschnitts, Institut für Baustatik und Konstruktion, ETH Zürich, Research Report Nr. 204, Birkhäuser Verlag, Basel, Switzerland

Steiger R, Fontana M (2005) Bending moment and axial force interacting on solid timber beams. Mater Struct 38(279):507-513 
Thelandersson S (1995) Step 3/11: Deformations in timber structures. In: Holzbauwerke nach Eurocode 5, Step 3: Grundlagen, Entwicklungen, Ergänzungen, Informationsdienst Holz. Arbeitsgemeinschaft Holz e. V, Düsseldorf

Thunell B (1941) Über die Elastizität schwedischen Kiefernholzes. Holz Roh- Werkst 4(1):15-18

Ylinen A (1942) Über den Einfluss des Spätholzanteiles und der Rohwichte auf die Festigkeits- und elastischen Eigenschaften des Nadelholzes. Acta forest. Fenn. 5:1. Cited In: Kollmann FFP, Côté Jr. WA (Ed.): Principles of Wood Science and Technology, vol 1: Solid Wood, Springer, Berlin, 1968, pp 346 